\title{
Anti-oxidant, Anti-inflammatory, Anti-proliferative and Anti-microbial activities (In vitro) of Indigofera hirsuta and Afrormosia laxiflora
}

\author{
Muhammad B. Y ${ }^{* 1,2}$, Adamu RM ${ }^{4}$, Enemali MO ${ }^{2}$, Abba Babandi ${ }^{3}$ \\ ${ }^{1}$ Department of Biochemistry, Faculty of Science, Alexandria University, Alexandria, Egypt \\ ${ }^{2}$ Department of Biochemistry and Molecular Biology, Faculty of Science, Nasarawa State University Keffi, Nigeria \\ ${ }^{3}$ Federal Medical Centre Keffi, Nigeria \\ ${ }^{4}$ Department of Biochemistry, Bayero University Kano Nigeria
}

\author{
DOI: $10.36348 /$ sjmps.2019.v05i11.002 \\ | Received: 21.10.2019 | Accepted: 28.10.2019| Published: 11.11.2019 \\ *Corresponding author: Muhammad BY
}

Abstract

This study highlights the characterization and biological activities (in vitro) of root extracts of Indigofera hirsuta (Ih-E) and Afrormosia laxiflora (Al-E). The results showed that total phenolic and flavonoid contents in dry Ih-E were $54.38 \mathrm{mg}$ and $116.03 \mathrm{mg} / \mathrm{gram}$, respectively, while in Al-E were $170.46 \mathrm{mg}$ and $80.23 \mathrm{mg} / \mathrm{gram}$. Both extracts exhibited antioxidant activities since they decreased lipid peroxidation, but increased antioxidant activities and anti-inflammatory activities as shown from inhibition of RBC haemolysis and inhibition of albumin denaturation. Also, they have cytotoxic effect against normal BHK-21 and HepG2 where $\mathrm{IC}_{50}$ for $\mathrm{Ih}-\mathrm{E}$ were $309 \mu \mathrm{g} / \mathrm{ml}$ and $95 \mu \mathrm{g} / \mathrm{ml}$, respectively (selectivity

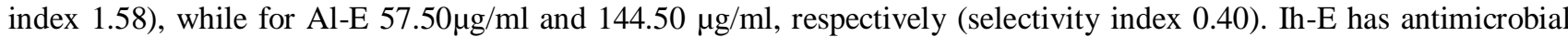
activities towards Pseudomonas aeruginosa, Staphylococcus aureus, Vibrio species and E-coli, while Al-E showed no antimicrobial activities. Conclusion: Both extracts possessed antioxidant, anti-inflammatory and anticancer activities, thus, can be used as pharmacological tools.

Keywords: Indigofera hirsuta root; Afrormosia laxiflora root, Antioxidant; anticancer; anti-inflammatory; antimicrobial. Copyright @ 2019: This is an open-access article distributed under the terms of the Creative Commons Attribution license which permits unrestricted use, distribution, and reproduction in any medium for non-commercial use (NonCommercial, or CC-BY-NC) provided the original author and source are credited.

\section{INTRODUCTION}

Plants (roots stem, fruits and leaves) contain secondary metabolites, which have various biological activities. The secondary metabolites could inhibit or modulate inflammatory response and oxidative stress (OS); which in turn, could prevent or treat pathological conditions [1]. Free radicals (F R) are fundamental to any biochemical process and represent an essential part of aerobic life and metabolism [2]. FRs include reactive oxygen species (ROS) and reactive nitrogen species (RNS). The most common ROS are superoxide anion radical $\left(\mathrm{O}_{2}-\bullet\right)$ hydrogen peroxide $\left(\mathrm{H}_{2} \mathrm{O}_{2}\right)$, peroxy radical (ROO•), hydroxyl $\left(\mathrm{OH}^{-}\right)$radicals while $\mathrm{RNS}$ include nitric oxide (NO) nitrogen dioxide $\left(\mathrm{NO}_{2}^{\bullet}\right)$, nitrite/nitrate and peroxy nitrite anion (ROO•) [2, 3]. Under normal circumstances, homeostasis exists between ROS/RNS and antioxidants. [4]. Antioxidants include both enzymatic such as superoxide dismutase (SOD), glutathione peroxidase (GPx), catalase, glutathione reductase and non-enzymatic such as glutathione, Vitamins A, C and among others [5]. However, excess production of ROS/RNS or deficiency of antioxidants could lead to OS stress, characterized by tissue injury, inflammation, LPO, proteins and DNA- damage, increased mutation rate within cells and thus promoting oncogenic transformation [6]. In addition, OS can trigger signalling pathways hence contribute to tumour development through regulation of cellular proliferation, angiogenesis and metastasis [7].

On the other hand, the increase in incidence of drug-resistance and adverse effect have made it necessary for scientists and pharmaceutical companies to search for drugs from natural sources [8]. Out of 109 new antibacterial drugs, approved in the period 19812006, 69\% got their root from medicinal plants and other natural compounds, and $21 \%$ of antifungal drugs were natural derivatives or compounds mimicking natural products [9].

Nigeria is a country that is blessed with vast arrays of flora most of which are yet to be discovered or utilized maximally, to arrive at a drug. Some of these florae used in Nigerian traditional medicine include; Afrormosia laxiflora (Hausa name: Makarho) is one of the commonest trees of the savanna and dry dense forest found in Niger, Nigeria, Senegal, and other West African countries. Traditionally, it is used as an 
antiseptic, anti-inflammatory, antipyretic and analgesic agent The bark is used in the treatment of oedema, insanity, paralysis, epilepsy, gout and stomach problems; while the root is used in diarrhoea and dysentery $[10,11]$. The leaves are used in eye complaints and oral problems. It is also used in North Central Nigeria in the treatment of HIV by traditional doctors, as intoxicant and for body pains [12].

\section{Indigofera (Hausa /Fulani name:}

Hakwoi/kaikayi; H) is a large genus of about 700 species of flowering plants that belongs to the Fabaceae family. It is commonly known as hairy Indigo, it originated from Africa and Asia but now widespread and naturalized in Australia and Southern Asia [13]. Hairy indigo is primarily found in cultivated areas, in grassland, savannah, and forests, and on river banks [14]. It is used as chest medicine; leaves are used to boost immunity in infant, for urinary tract infections, treatment of impotency and weak erection. The leaves are used against diarrhoea (and stomach problems. Whole plant paste is applied as an external application for back ache, for eye ball injury and inflammation of eye lids $[14,15]$. It was reported that I. hirsuta leaves extracts has antibacterial activity against E. coli, $B$. subtilis, Ps. aeruginosa, S. aureus [15].This study was designed to determine (in vitro) anti-oxidant, antiinflammatory, anti-microbial and anti-proliferative activities of these Nigerian medicinal plants.

\section{MATERIALS AND METHODS}

\section{Chemicals and Reagents}

Trichloro acetic acid (TCA), thiobarbituric acid (TBA), butylated hydroxytoluen (BHT), 1,1diphenyl-2picryl hydrazyl (DPPH) radical, pnitrophenyl-b-D-glucopyranoside (PNPG), 5,5'dithiobis 2-nitrobenzoic acid (DTNB), napthylenediamine hydrochloride, sulphanilamide, 3[4,5-dimethylthiazole-2-yl]-2,5-diphenyltetrazolium bromide (MTT) and sodium nitroprusside were purchased from Sigma Chemical Co. (St. Louis, Mo, USA). Organic solvents of HPLC-grade ethanol 95\% obtained from Merck (USA). All other chemicals and reagents were of analytical grade.

\section{Collection and extraction of plant samples}

Plants samples (which include the roots, leaves and fruits) were collected in January 2015 from Keffi, Nasarawa State, Nigeria. The roots were authenticated at the Department of plant science and Biotechnology, Nasarawa State University, Keffi and Voucher specimens (NSUKH Al;1 0155, and NSUKH Ih; 0156) were deposited at the herbarium. The roots were washed with water, cut into pieces, grinded with pestle and mortar, and allowed to dry in the shade. A small mesh sieve was used to obtain small particles of about $100 \mu \mathrm{m}$. The larger particles were discarded while the powdered kept in air tight plastic container until further use. The dried powdered root of each plant (100g) was exhaustively defatted with petroleum ether then soaked in $300 \mathrm{ml}$ ethanol $(95 \%)$ and left for 48 hours. The extracts were obtained by filtration, then concentrated using rotary evaporator at $55^{\circ} \mathrm{C}$ and $100 \mathrm{rpm}$ (BÜchi, Switzerland) then lyophilized (DISHI, DS-FD-SH10, Xian Heb Biotechnology Co, China) to obtain extracts in powdered form. The extracts were kept at $-20^{\circ} \mathrm{C}$ until used.

\section{Human Blood}

Human participants and their specimen (blood) met the ethical standards for donor agreement, made mandatory by national regulatory bodies. Participants signed informed consent for the use of their blood in this study. Blood samples ( $2 \mathrm{mls}$ each) were collected from five healthy individuals who did not take any medication two weeks prior to collection.

\section{Animals}

Experimental procedure was approved by Alexandria University Animal Ethics Committee (AEC), and animals received tender care as contained in the guide lines of National Health and Medical Research Council (NHMRC), Arab Republic of Egypt. Six male rats (150-200g bodyweight) were obtained from animal of house of medical research institute, Alexandria University (Egypt). Animals were left to adapt to our laboratory for two weeks before the experiment. Liver was isolated from the animals after anaesthesia and washed in cold saline, and then one gram of each liver was homogenized in $9 \mathrm{ml}$ phosphate buffer saline. The homogenate was centrifuged at 3000 and metabolites containing supernatant was carefully decanted for further biochemical assessments.

\section{Phytochemical composition}

Dried powdered plants root extracts were spechtrophometrically screened for total phenolic and flavonoids. The Folin-ciocalteu reagent method as described by Demiray et al. [16] was employed to determine the total phenolic contents of the plant extracts. While Aluminium chloride colorimetric method was used for total flavonoids determination [5] .

\section{Assessment of antioxidant activities}

The anti-oxidant activities of the plants root extracts were determined by DPPH Radical Scavenging Assay (1,1-diphenyl-2picryl hydrazyl) [17]. The method of Halliwel and Barry. with little modification [18] was used to assay HO. Nitric oxide scavenging activity was estimated using Griess reagent [19]. The lipid peroxidation was determined through the estimation of malondialdehyde formed [20]. Glutathione (GPx) peroxidase activity (EC NO:1.11.19) activity was determined by the method of Paglia and Valentia [21] and Determination of superoxide dismutase (SOD) activity (EC NO:1.15.1.1) by the method of Markland and Marklund [22]. 
Assessment of in vitro anti-inflammatory activity

Inhibition of albumin denaturation and Membrane stabilization test were used to test for antiinflammatory activity. [23]

\section{Antimicrobial assay}

The indicator bacteria used in current investigation were Pseudomonas aeruginosa ATCC: 8739, Staphylococcus aureus ATCC: 6538, Escherichia coli ATCC 8739 and Vibrio sp.

The assay was carried out as described by Nassir et al.[24] And Anti-fungal activity of the samples was determined by disk diffusion method on Muller Hinton agar (MHA) medium. [25].

\section{Cytotoxicity assay by 3-[4,5-dimethylthiazole-2-yl]-} 2,5-diphenyltetrazolium bromide (MTT)

Exponentially growing HepG-2 and BHK-21 cells were trypsinized, counted and seeded at the appropriate densities (5000 cells / $0.33 \mathrm{~cm} 2$ well) into 96-wells microtiter plate. Cells were incubated in a humidified atmosphere at $37^{\circ} \mathrm{C}$ for $24 \mathrm{~h}$. Then, cells were exposed to different extracts for $72 \mathrm{~h}$. By the end of the treatment period, media were removed, cells were incubated with $200 \mu \mathrm{MTT}$ solution / well and allowed to metabolize the dye into a coloured-insoluble formazan complex for $2 \mathrm{~h}$. Media were discarded from the wells, then $200 \mu \mathrm{l}$ well acidified isopropanol were added per well, the plates were then covered with aluminium foil and continuously shook using plate shaker for $30 \mathrm{~min}$ to dissolve the formed formazan crystals. Absorbance was measured at $570 \mathrm{~nm}$ using a Microplate Reader. Cell viability was plotted against different extract concentrations to determine the $\mathrm{IC}_{50}$ [26].

\section{STATISTICAL ANALYSIS}

All data were expressed as mean \pm standard deviation (SD). The differences were statically significant at $\mathrm{P}<0.05$. Statistical analyses were carried out using primers of Biostatistics program $\mathrm{V}_{5}$ for analysis of unpaired student $\mathrm{T}$ - Test and one way (ANOVA).

\section{RESULTS}

\section{Characterization of the plants extracts}

Total phenolic content: The result shows that the total phenolic content in Ih-E and Al-E are 54.38 $\mathrm{mg}$ and $170.46 \mathrm{mg}$ per gram dry extract, as Gallic acid equivalent respectively.

HPLC analysis of polyphenolic compounds: The result expressed in $\mathrm{mg} / \mathrm{g}$ (Figure $1 \mathrm{a}$ and $\mathrm{b}$ ) shows that, Ih-E contains; caffeic (3.61 mg), 3,4Dicaffeolylquinic acid 4,4-Dicaffeolylquinic acid vanillic acid $(0.47 \mathrm{mg})$, epigallocatechin gallate (0.28mg), salicylic acid $(0.0013 \mathrm{mg})$, while Al-E contains; Gallic acid $(4.33 \mathrm{mg}), 2,5$-dihydroxy benzoic acid $(0.29 \mathrm{mg})$, vanillic acid $(0.087 \mathrm{mg})$, and syringic acid $(0.0015 \mathrm{mg})$, respectively as showed in fig.1.

Total flavonoids content: The result shows that, the total flavonoid content in Ih-E and Al-E are $170.46 \mathrm{mg}$ and $80.23 \mathrm{mg}$ per dry extract as quercetin equivalent respectively.

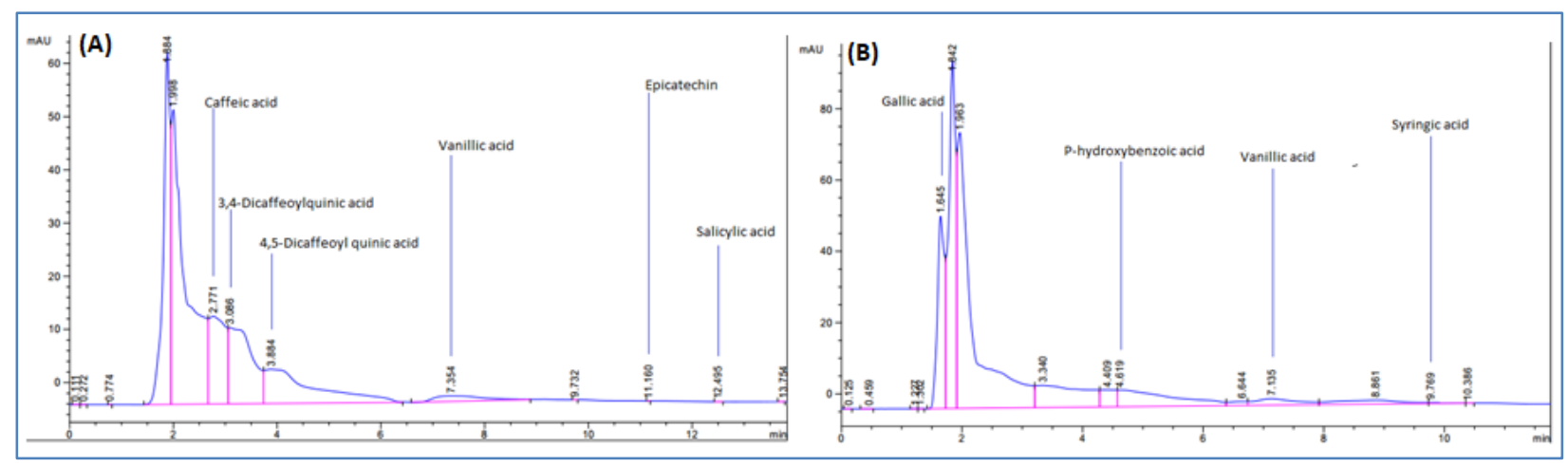

Fig-1: HPLC chromatogram of Studied plants: (A) Ih--E (B) Al-E

\section{Free radical scavenging and antioxidant activity}

$D P P H$ : Figure 2a shows that $\mathrm{Ih}-\mathrm{E}$ and Al-E have DPPH scavenging activity and these activities increase in concentration dependent manner. It also shows that Ih-E has better activity than Al-E.

Hydroxyl radical scavenging activity: Figure $2 \mathrm{~b}$ shows that Ih-E and Al-E have HO scavenging activity and these activities increase in concentration dependent manner. It also shows that Ih-E has better activity than Al-E.
Nitric oxide radical scavenging activity: Figure $2 \mathrm{c}$ shows that Ih-E and Al-E have NO. scavenging activity and these activities increase in concentration dependent manner. It also shows that IhE has better activity than Al-E.

Inhibition of lipid peroxidation activity: Figure $2 \mathrm{~d}$ shows that $\mathrm{Ih}-\mathrm{E}$ and Al-E have scavenging/antioxidant activity by impeding lipid peroxidation and these activities increase in 


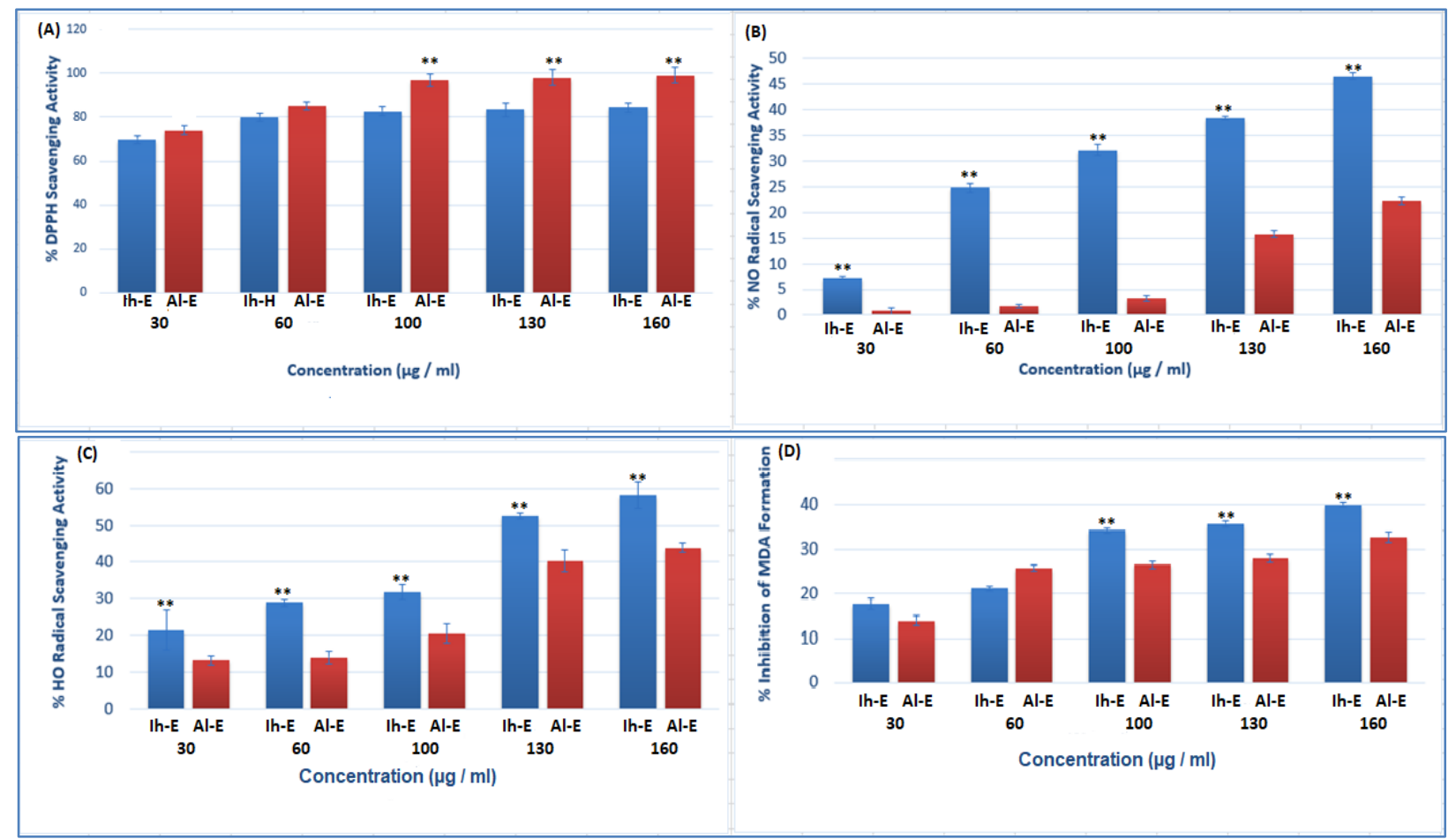

Fig-2: Radical scavenging effect of Ih-E and Al-E. (A): DPPH (B) hydroxyl radical (C): Nitric oxide radical (D) Inhibition of MDA formation. Where Ih-E: Indigofera hirsuta and Al-E: Afromosia laxiflora. Data are presented as mean $\pm \mathrm{SD}(\mathrm{n}=3)$, values differ within column significantly at $* * \mathbf{P}<0.05$

\section{Antioxidant activity}

SOD activity: Figure 3a. shows that Ih-E and Al-E cause significant activation in SOD activity and these activities increase in concentration dependent manner. It also shows that Ih-E has better activity than Al-E
GPX activity: Figure 3b. shows that Ih-E and Al-E cause significant activation in SOD activity and these activities increase in concentration dependent manner. It also shows that Ih-E has better activity than Al-E.

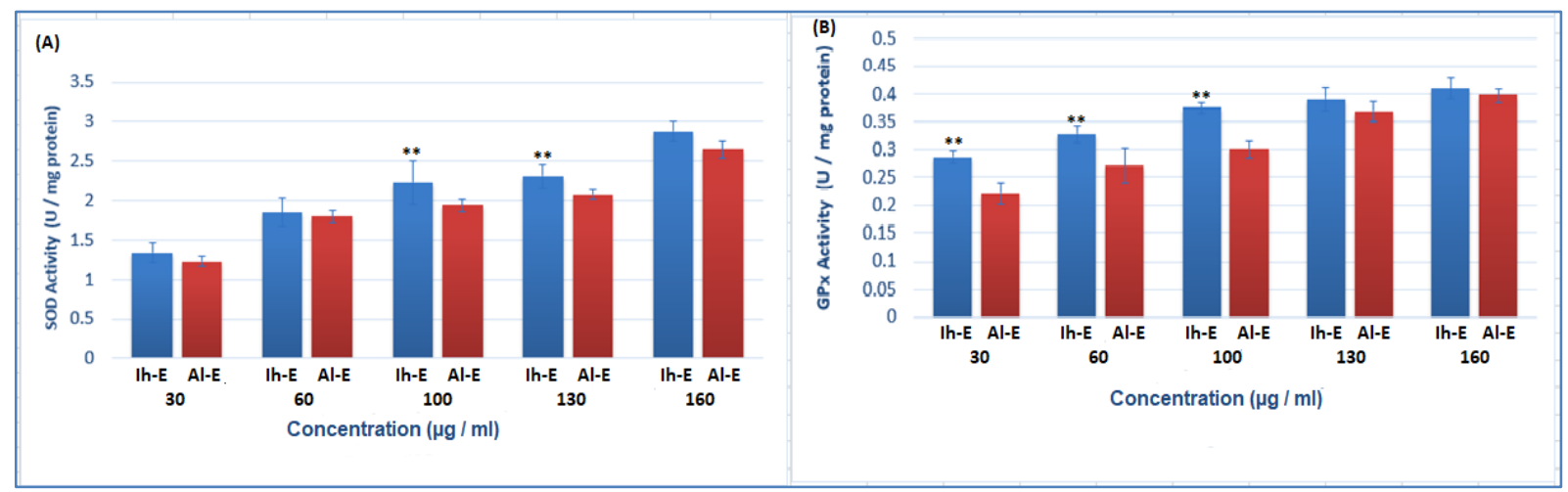

Fig-3: Effect of different concentrations of studied plants on some antioxidant enzymes activities in rat liver homogenate (A): Superoxide dismutase (SOD) and (B): Glutathione peroxidase (GPx). Where Ih-E: Indigofera hirsuta and Al-E: Afromosia laxiflora. Data are presented as mean \pm SD $(n=3)$ values differ within column significantly at $* * \mathbf{P}<0.05$.

\section{Anti-inflammatory activity}

Inhibition of RBC haemolysis: Figure 4a shows that Ih-E and Al-E have activity against hypotonic solution induced RBC haemolysis and these activities increase in concentration dependent manner. It also shows that Ih-E has better activity than Al-E. 
Inhibition of albumin denaturation: Figure $4 \mathrm{~b}$ shows that Ih-E and Al-E have activity against heat induced albumin denaturation and these activities increase in concentration dependent manner. It also shows that Ih-E has better activity than Al-E.
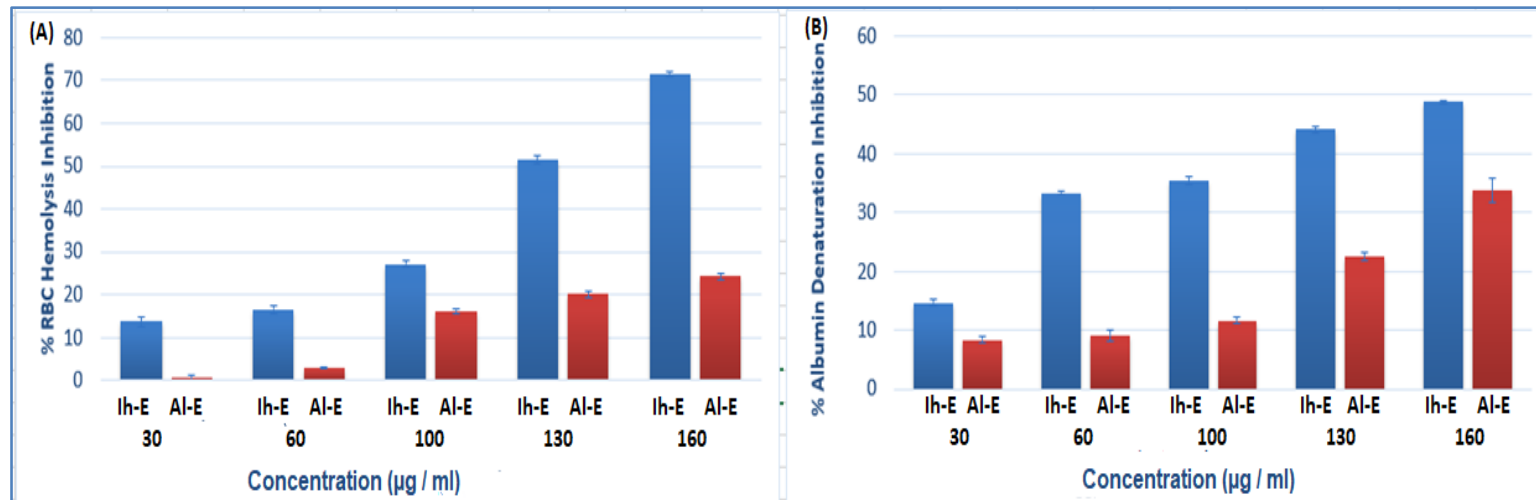

Fig-4: The anti-inflammatory activities of studied plants at different concentrations. (A): percentage inhibition of RBC haemolysis and (B): Percentage inhibition of albumin denaturation. Where Ih-E: Indigofera hirsuta and AlE: Afromosia laxiflora. Data are presented as mean \pm SD $(n=3)$ values differ significant at $P^{* *}<0.05$.

Cytotoxicity assay against normal and cancerous cells lines

Figure 5 shows the activity of Ih-E against normal BHK-21 and HepG2 with an $\mathrm{IC}_{50}$ of $309 \mu \mathrm{g} / \mathrm{ml}$ and $195 \mu \mathrm{g} / \mathrm{ml}$ respectively; given a selectivity index of 1.58. Whereas, Al-E revealed an $\mathrm{IC}_{50}$ of $478.00 \mu \mathrm{g} / \mathrm{ml}$ and $478.60 \mu \mathrm{g} / \mathrm{ml}$ respectively; given a selectivity index of 0.99 .

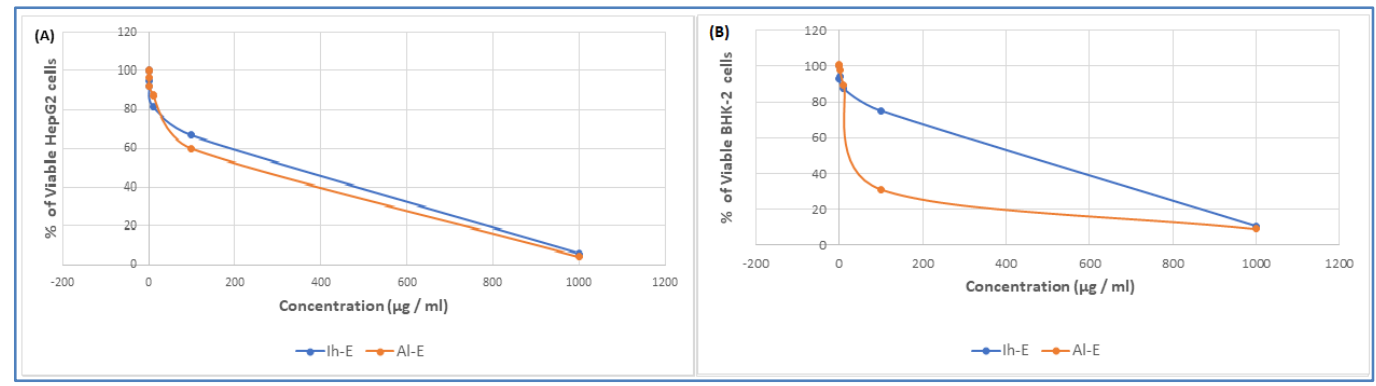

Fig-5: Effect of different concentrations of Ih-E and Al-E on normal and cancer cells viability. (A): Activity HepG2 cells line and (B): Activity against BHK-21 cells line. Where Ih-E: Indigofera hirsuta and Al-E: Afromosia laxiflora

\section{Antimicrobial activity}

The Effect of Ih-E and Al-E on selected pathogens is described in the (Table1). Ih-E has activity against all the pathogens while Al-E has activity against only two.

Table-1: Antimicrobial activity of plants' extract

\begin{tabular}{|c|c|c|c|c|c|}
\hline \multirow{2}{*}{$\begin{array}{c}\text { Extract } \\
(\mathbf{1 0 0} \boldsymbol{\mu g} / \mathbf{m l})\end{array}$} & \multicolumn{5}{|c|}{ Inhibition zones (mm) } \\
\cline { 2 - 6 } & Ps aeruginosa & Staph. aureus & Vibrio $\boldsymbol{S p}$. & C. albicans & E. coli \\
\hline $\mathrm{Ih}-\mathrm{E}$ & 27 & 14 & 11 & $-\mathrm{ve}$ & 10 \\
\hline $\mathrm{Al}-\mathrm{E}$ & $-\mathrm{ve}$ & $-\mathrm{ve}$ & $-\mathrm{ve}$ & $-\mathrm{ve}$ & $-\mathrm{ve}$ \\
\hline
\end{tabular}

The table describes the effect of Ih-E and Al-E against selected microbial pathogens culture after 24 hrs. Ih-E has activity against all pathogens tested except candida albicans while Al-E has no activity. Where IhE: Indigofera hirsuta extract and Al-E: Afrormosia laxiflora extract

\section{DISCUSSION}

The result of phytochemical analysis showed that the total phenolic content in Ih-E and Al-E are $70.61 \mathrm{mg}$ and $40.76 \mathrm{mg}$ per gram dry extract, as Gallic acid equivalent, respectively. While total flavonoids are $100.44 \mathrm{mg}$ and $0.51 \mathrm{mg}$ per dry extract as quercetin equivalent respectively. HPLC analysis revealed both extracts especially Ih-E being very rich in flavonoids. 
Previous phytochemical studies showed that Ih-E contains sterols, triterpenes, flavonoids, saponins, coumarins and tannins. while TLC revealed the presence of Apigenin, Genistein, Rutin and quercetin [27].

ROS are generally generated from aerobic metabolism in the mitochondria and microsomes as well as metabolism of xenobiotics.[28]. Oxidative stress results from the imbalance between ROS/RNS and antioxidants mechanisms of the body [29]. Recently natural products are used as a source of pharmaceutical antioxidants; therefore, in this study the antioxidant, anti-inflammatory, anticancer and antimicrobial activities of Ih-E and Al-E were evaluated.

Recently natural products are used as a source of pharmaceutical antioxidants; therefore, in this study the antioxidant, anti-inflammatory, anticancer and antimicrobial activities of $\mathrm{Ih}-\mathrm{E}$ and $\mathrm{Al}-\mathrm{E}$ were evaluated. The result of this study showed that the $\mathrm{IC}_{50}$ of Ih-E for DPPH, HO $\mathrm{NO} \cdot$ were estimated as $30 \pm 1.5$ $\mu \mathrm{g} / \mathrm{ml}, \quad 135 \pm 0.8 \mu \mathrm{g} / \mathrm{ml}$ and $167 \pm 3.6 \mu \mathrm{g} / \mathrm{ml}$ respectively while that of Al-E were found to be $13 \pm$ $2.1 \mu \mathrm{g} / \mathrm{ml}, 185 \pm 1.6 \mu \mathrm{g} / \mathrm{ml}$ and $250 \pm 3.8 \mu \mathrm{g} / \mathrm{ml}$ respectively. This indicates that both extracts exhibited good scavenging activities for the various radicals. These activities increased with increase in concentrations of the extracts. Similarly, Ih-E and Al-E inhibited TBA-MDA adduct formation ex vivo. Compounds such as, caffeic acid, catechins and Vanillic acid identified in Ih-E and Al-E have been found to possess free radical scavenging and antioxidant activity [30]. These could explain also why Ih-E showed greater activity compared to Al-E; since it contains more of these compounds.

In addition, the results showed that both Ih-E, and Al-E increased the activity of SOD and GPx in liver homogenate ex vivo. This activation was increased with increased concentrations of extracts. Ih-E exhibited significantly $(\mathrm{P}<0.05)$ greater activation of the enzyme's activity compared to Al-E. These results agree to the previous studies which reported that flavonoids increase SOD, GPx and Catalase activity in vitro[31] and in vivo. [5, 32].

On the other hands, Ih-E showed better antiinflammatory activities than Al-E such that Ih-E inhibited HRBC haemolysis and heat induced albumin denaturation (with $\mathrm{IC}_{50} 120 \mu \mathrm{g} / \mathrm{ml}$ and $152 \mu \mathrm{g} / \mathrm{ml}$ respectively). While Al-E only slightly inhibited HRBC haemolysis and heat induced albumin denaturation (with $\mathrm{IC}_{50}: 370 \mu \mathrm{gand} 306 \mu \mathrm{g} / \mathrm{ml}$ respectively). Since cell membranes are similar in component and architecture, $\mathrm{HRBC}$ is therefore, like lysosomal membrane. For this reason, protection of HRBC membrane from lysis due to hypo tonicity and inhibition of heat induced albumin denaturation are considered as tests for antiinflammatory activity[33]. An inflammatory process resulting from infection and/or damaged tissues accompanied by the release of lysosomal enzymes (such as glycosidases, proteases and sulphases) and inflammatory mediators, is considered a hallmark for many pathological conditions; especially fibrosis and cancer[34]. Nonsteroidal anti-inflammatory drugs (NSAIDs) impede inflammation by either inhibiting lysosomal enzymes or by stabilizing the lysosomal membrane [35]. For both RBC membrane stabilization and albumin denaturation assay, our extracts showed activity in concentration dependent manner. Similarly, NO which could act as pro oxidant or an inflammatory mediator was found to be decreased by the extracts in concentration dependent manner (Fig.2) with Ih-E having significantly $(\mathrm{P}<0.05)$ higher activity. These higher anti-inflammatory activities of Ih-E could be attributed to the presence of salicylic acid which is known anti-inflammatory and a pyretic drug readily available in the pharmacy shops. This suggests the possibility of Ih-E to serve as possible pharmaceutical lead compound to isolate antioxidant and antiinflammatory drug.

In vitro cytotoxicity (MTT) assay against BHK-21 and HepG2 cell lines, revealed that Both Ih-E and $\mathrm{Al}-\mathrm{E}$ have an $\mathrm{IC}_{50}$ of less than $500 \mu \mathrm{g} / \mathrm{ml}$, hence considered cytotoxic [36]. Ih-E showed higher activity against HepG2 $\left(\mathrm{IC}_{50}: 195 \mu \mathrm{g} / \mathrm{ml}\right)$ than BHK-21 cell line $\left(\mathrm{IC}_{50}: 302 \mu \mathrm{g} / \mathrm{ml}\right.$ ) and selectivity index (SI) of 1.58 . Similar result was reported in some members of this genus [37]. However, to the best of our knowledge this is the first finding on the ethanol root extract of this species against cancer cell line. On the other hand, Al-E showed higher cytotoxicity against normal BHK-21 cell line $\left(\mathrm{IC}_{50}: 57.50 \mu \mathrm{g} / \mathrm{ml}\right)$ than HepG2 cell lines $\left(\mathrm{IC}_{50}\right.$ : $144.50 \mu \mathrm{g} / \mathrm{ml})$. The S.I. was found to be 0.4 . The variation in the cytotoxicity of Ih-E and Al-E could be related to differences in their phytochemical compositions.

The result in Table 1 shows that plant Ih-E has activity against all the pathogenic organisms tested except candida albicans. This finding agrees to the results of Nopsiri et al. who found that Ih-E has activity against all the pathogens tested including $S$. typhimurium and $K$ pneumoniae [38]; tested. This agrees to the findings of Suvarnalatta et al. and Latha et al. [15, 39]. On the other hand, Ih-E showed no activity against all the pathogens.

\section{CONCLUSIONS}

This study established the potential of Ih-E and Al-E as antioxidant, anti-inflammatory and anticancer agents. Moreover, the results showed that Ih-E has antimicrobial activity against. Currently we are studying the biological activities of these extracts (in vivo). 


\section{ACKNOWLEDGEMENTS}

We would like to acknowledge the contribution of Prof. Muhammad Tamar of the Faculty of Pharmacy Al-Azhar University, Cairo, Egypt, for providing us enabling atmosphere to carry out the cytotoxicity studies.

\section{REFERENCE}

1. Asowata-Ayodele, A. M., Otunola, G. A., \& Afolayan, A. J. (2016). Assessment of the polyphenolic content, free radical scavenging, antiinflammatory, and antimicrobial activities of acetone and aqueous extracts of Lippia javanica (Burm. $\quad$ F.) spreng. Pharmacognosy magazine, 12(Suppl 3), S353.

2. Li, S., Tan, H. Y., Wang, N., Zhang, Z. J., Lao, L., Wong, C. W., \& Feng, Y. (2015). The role of oxidative stress and antioxidants in liver diseases. International journal of molecular sciences, 16(11), 26087-26124.

3. Kim-Shapiro, D. B., \& Gladwin, M. T. (2014). Mechanisms of nitrite bioactivation. Nitric Oxide, 38, 58-68.

4. Abdel-Rahman, S., Shaban, N., Haggag, A., Awad, D., Bassiouny, A., \& Talaat, I. (2015). Inhibition of $\mathrm{NF}-\kappa \mathrm{B}, \mathrm{Bcl}-2$ and $\mathrm{COX}-2$ gene expression by an extract of Eruca sativa seeds during rat mammary gland carcinogenesis. Asian Pac J Cancer Prev, 16, 8411-8418.

5. Shaban, N. Z., El-Kersh, M. A., Bader-Eldin, M. M., Kato, S. A., \& Hamoda, A. F. (2014). Effect of Punica granatum (pomegranate) juice extract on healthy liver and hepatotoxicity induced by diethylnitrosamine and phenobarbital in male rats. Journal of medicinal food, 17(3), 339-349.

6. Almeda-Valdés, P., N.E.(2017). Aguilar-Olivos, M. Uribe, and N. Méndez-Sánchez, Chapter 25 The Metabolic Syndrome, Oxidative Stress, and the Liver A2 - Muriel, Pablo, in Liver Pathophysiology. 2017, Academic Press: Boston, 323-329.

7. Affo, S., L.-X. Yu., \& R.F. Schwabe. (2017). The Role of Cancer-Associated Fibroblasts and Fibrosis in Liver Cancer. Annual Review of Pathology: Mechanisms of Disease, 12(1), 153-186.

8. Roca, I., M. Akova, F. Baquero, J. Carlet, M. Cavaleri, S. Coenen, J. Cohen, D. Findlay, I. Gyssens., \& O. Heure. (2015). The global threat of antimicrobial resistance: science for intervention. New microbes and new infections, 6, 22-29.

9. Savoia, D. (2012). Plant-derived antimicrobial compounds: alternatives to antibiotics. Future microbiology, 7(8), 979-990.

10. Burkill, H. M. (1994). The useful plants of west tropical Africa. Volume 2: Families EI (No. Edn 2). Royal Botanic Gardens.

11. Duke, J.A.(2002). Handbook of medicinal herbs. 2002: CRC press.
12. El-Ghani, M.M.A. (2016). Traditional medicinal plants of Nigeria: an overview. Agriculture and Biology Journal of North America, 7, 220-247.

13. Duke, J.(2012). Handbook of legumes of world economic importance. 2012: Springer Science \& Business Media.

14. Gafar, M.K., I. Adams Ph.D, F. Atiku, A.M. Hassan., \& I.J. (2011). Peni, Proximate and Mineral Composition of the Leaves of Hairy Indigo (Indigofera astragalina), 168-175.

15. Suvarnalatha, A., N. Yasodamma, C. Alekhya., \& D. Chaithra. (2014). Pharmacognostic studies of Indigofera hirsuta L. International Journal of Pharmacy and Pharmaceutical Sciences, 6(4), 111117.

16. Demiray, S., M. Pintado, and P. Castro. (2009). Evaluation of phenolic profiles and antioxidant activities of Turkish medicinal plants: Tilia argentea, Crataegi folium leaves and Polygonum bistorta roots. World Academy of Science, Engineering and Technology, 54, 312-317.

17. Blois, M.S. (1958). Antioxidant determinations by the use of a stable free radical. nature, 181(4617), 1199-1200.

18. Halliwell, B. (1994). Free radicals, antioxidants, and human disease: curiosity, cause, or consequence? The lancet, 344(8924), 721-724.

19. Patel Rajesh, M., \& J. Patel Natvar. (2011). In vitro antioxidant activity of coumarin compounds by DPPH, super oxide and nitric oxide free radical scavenging methods. Journal of advanced pharmacy education \& research, 1, 52-68.

20. Gutteridge, J.M., \& B. Halliwell. (1990). The measurement and mechanism of lipid peroxidation in biological systems. Trends in biochemical sciences, 15(4), 129-135.

21. Paglia, D.E., \& W.N. Valentine. (1967). Studies on the quantitative and qualitative characterization of erythrocyte glutathione peroxidase. The Journal of laboratory and clinical medicine, 70(1), 158-169.

22. Marklund, S., \& G. Marklund. (1974). Involvement of the superoxide anion radical in the autoxidation of pyrogallol and a convenient assay for superoxide dismutase. The FEBS Journal, 47(3), 469-474.

23. Mizushima, Y., \& M. Kobayashi. (1968). Interaction of anti-inflammatory drugs with serum proteins, especially with some biologically active proteins. Journal of Pharmacy and Pharmacology, 20(3), 169-173.

24. Nasir, B., H. Fatima, M. Ahmed., \& I. Haq. (2015). Recent trends and methods in antimicrobial drug discovery from plant sources. Austin J Microbiol, 1(1), 1-12.

25. Barani, K., S. Manipal, D. Prabu, A. Ahmed, P. Adusumilli, \&., C. Jeevika. (2014). Anti-fungal activity of Morinda citrifolia (noni) extracts against Candida albicans: An in vitro study. Indian Journal of Dental Research, 25(2), 188. 
26. Scudiero, D.A., R.H. Shoemaker, K.D. Paull, A. Monks, S. Tierney, T.H. Nofziger, M.J. Currens, D. Seniff., \& M.R. Boyd. (1988). Evaluation of a soluble tetrazolium/formazan assay for cell growth and drug sensitivity in culture using human and other tumor cell lines. Cancer research, 48(17), 4827-4833.

27. Alowanou, G., A. Olounlade, E. Azando, V. Dedehou, F. Daga., \& M. Hounzangbe-adote. (2015). A review of Bridelia ferruginea, Combretum glutinosum and Mitragina inermis plants used in zootherapeutic remedies in West Africa: historical origins, current uses and implications for conservation. Journal of Applied Biosciences, 87(1), 8003-8014.

28. Shaban, N.Z., M.A. El-Kersh, F.H. El-Rashidy, and N.H. Habashy. (2013). Protective role of Punica granatum (pomegranate) peel and seed oil extracts on diethylnitrosamine and phenobarbital-induced hepatic injury in male rats. Food chemistry, 141(3), 1587-1596.

29. Boufadi, Y.M., J. Soubhye, A. Riazi, A. Rousseau, M. Vanhaeverbeek, J. Nève, K.Z. Boudjeltia, and P. Van Antwerpen. (2014). Characterization and antioxidant properties of six Algerian propolis extracts: ethyl acetate extracts inhibit myeloperoxidase activity. International journal of molecular sciences, 15(2), 2327-2345.

30. Shaban, N., S. Abdel-Rahman, A. Haggag, D. Awad, A. Bassiouny, and I. Talaat. (2016). Combination between taxol-encapsulated liposomes and Eruca sativa seed extract suppresses mammary tumors in female rats induced by 7,12 Dimethylbenz $(\alpha)$ anthracene. Asian Pac J Cancer Prev, 17, 117-23.

31. Molina, M.F., I. Sanchez-Reus, I. Iglesias., \& J. Benedi. (2003). Quercetin, a flavonoid antioxidant, prevents and protects against ethanol-induced oxidative stress in mouse liver. Biological and Pharmaceutical Bulletin, 26(10), 1398-1402.
32. Singh, J.P., A. Kaur, K. Shevkani., \& N. Singh. (2016). Composition, bioactive compounds and antioxidant activity of common Indian fruits and vegetables. Journal of food science and technology, 53(11), 4056-4066.

33. Shaikh, R.U., M.M. Pund., \& R.N. Gacche. (2016). Evaluation of anti-inflammatory activity of selected medicinal plants used in Indian traditional medication system in vitro as well as in vivo. Journal of traditional and complementary medicine, 6(4), 355-361.

34. Nabavi, S., M. Ebrahimzadeh, S. Nabavi, A. Hamidinia., \& A. Bekhradnia. (2008). Determination of antioxidant activity, phenol and flavonoids content of Parrotia persica Mey. Pharmacologyonline, 2, 560-567.

35. Bajpai, S., R. Pathak., \&T. Hussain. (2014). Antiinflammatory activity of ethnobotanical plants used as traditional medicine: A review. Res. Rev. J. Bot. Sci, 3, 8-18.

36. Prayong, P., S. Barusrux., \& N. Weerapreeyakul. (2008). Cytotoxic activity screening of some indigenous Thai plants. Fitoterapia, 79(7), 598-601.

37. de Morais Lima, G.R., I.R.P. de Sales, M.R.D. Caldas Filho, N.Z.T. de Jesus, H. de Sousa Falcão, J.M. Barbosa-Filho, A.G.S. Cabral, A.L. Souto, J.F. Tavares., \& L.M. Batista. (2012). Bioactivities of the genus Combretum (Combretaceae): a review. Molecules, 17(8), 9142-9206.

38. Nopsiri, W., S. Chansakaow, S. Putiyanan, S. Natakankitkul, K. Nantachit, B. Khantawa., \& D. Santiarworn. (2015). Chemical constituents and antibacterial activity of volatile oils of Combretum latifolium Bl. and C. quadrangulare Kurz Leaves. CMUJ Nat Sci, 14, 245-256.

39. Latha, A.S., \& N. Yasodamma. (2015). Quantitative Phytochemical Evaluation of Indigofera hirsuta L. Plant Parts. 